\title{
HARAPAN KLIEN NAPZA SELAMA MENJALANI PROSES PEMULIHAN KETERGANTUNGAN JANGKA PANJANG
}

\author{
Rizqi Wahyu Hidayati ${ }^{1}$; Indah Winarni ${ }^{2}$; Septi Dewi Rachmawati ${ }^{2}$ \\ ${ }^{1}$ Program Studi Sarjana Keperawatan, Universitas Jendral Achmad Yani Yogykarta, Jl. Ringroad Barat, \\ Gamping Kidul, Ambarketawang, Kec. Gamping, Kabupaten Sleman, Yogyakarta, Indonesia 55294 \\ ${ }^{2}$ Program Magister Keperawatan Fakultas Kedokteran Universitas Brawijaya, Jl. Veteran, Ketawanggede, Kec. \\ Lowokwaru, Kota Malang, Jawa Timur 65145 \\ *ririzpl@gmail.com
}

\begin{abstract}
ABSTRAK
Penyalahgunaan NAPZA telah menjadi masalah global, termasuk Indonesia, khususnya Yogyakarta. Yogyakarta merupakan propinsi dengan prevalensi tertinggi yang menyalahgunakan narkoba di kalangan pelajar dan mahasiswa di Indonesia, dengan angka 2,8 (untuk pemakai aktif) dan 6,6 (yang pernah pakai). Penggunaan tersebut memiliki dampak negatif terhadap kesehatan baik secara fisik maupun psikologis. Sehingga dibutuhkan pemulihan untuk mengembalikan fungsi dan peran individu. Selama menjalani proses pemulihan, mereka memiliki harapan untuk kehidupannya. Maka, penelitian ini bertujuan untuk mengetahui harapan klien selamamenjalani proses pemulihanketergantungan NAPZA. Penelitian ini diharapkan mampu menggambarkan secara holistik mengenai harapanklien NAPZAselamamenjalani proses pemulihanjangkapanjang, sehingga metode yang digunakan yaitu kualitatif dengan design fenomenologi intepretatif. Partisipan yang diambil yaitu klien yang sudah keluar dari Panti Rehabilitasi Kunci Yogyakarta Sleman minimal 6 bulan (menjalanipemulihanjangkapanjang).Berdasarkan hasil analisis dari fenomenologi intepretatif terhadap 9 partisipan didapatkan hasil tema yaitu sebagai berikut: (1) Mempertahankan diri dari ego dan lingkungan yang menjerumuskan; (2) Difasilitasi menjadi mandiri untuk bangkit dari keterpurukan; dan (3) Mendapat kepercayaan dan cinta kasih secara utuh.
\end{abstract}

Kata kunci: harapan, pemulihan, NAPZA

\section{HOPE CLIENTS OF NAPZA DURING A LONG TERM RELIABLE RESTORATION RECOVERY PROCESS}

\begin{abstract}
Drug abuse has become a global problem, including Indonesia, especially Yogyakarta. Yogyakarta is the province with the highest prevalence of drug abuse among students in Indonesia, with 2.8 (for active users) and 6.6 (who have used it). These uses have a negative impact on health both physically and psychologically. So that recovery is needed to restore individual functions and roles. During the recovery process, they have hope for their lives. Therefore, this study aims to determine the client's expectations during the recovery process of drug addiction. This research is expected to be able to describe holistically about the expectations of NAPZA clients during a long recovery process, so that the method used is qualitative with interpretative phenomenological design. Participants taken were clients who had left the Yogyakarta Sleman Key Rehabilitation Institution for at least 6 months (undergoing long-term recovery). (2) Facilitated to be independent to rise from adversity; and (3) Gaining complete trust and love.
\end{abstract}

Keywords: hope, recovery, drug

\section{PENDAHULUAN}

Penyalahgunaan NAPZA telah menjadi masalah global, termasuk Indonesia. Kejadian ini dapat dilihat dari data pada tahun 2011 telah terdapat $2,23 \%$ atau 4,2 juta orang dari total penduduk (berusia $10-59$ tahun) (Aztri\&Milla, 2013). Di Yogyakarta merupakan propinsi dengan prevalensi tertinggi yang menyalahgunakan narkoba di kalangan pelajar dan mahasiswa di Indonesia, dengan angka 2,8 (untuk pemakai aktif) dan 6,6 (yang pernah pakai)(Betty \& Panel, 2007).

Pemulihan merupakan salah satu metode untuk meningkatkan koping dan resiliensi penyalahguna (Fredericks \& Samuel, 2014). 
Pemulihan tidak hanya berlangsung direhabilitasi saja, tetapi juga di komunitas serta berlangsung seumur hidup. Pemulihan jangka panjag di komunitas tersebut yang memiliki tantangan lebih tinggi dibandingkan di tempat rehabilitasi. Hal ini dikarenakan mereka bertemu dengan teman pemakai atau lingkungan baru, tetapi yang akrab dengan NAPZA. Ada rasa ingin menggunakan kembali zat tersebut jika melihat teman pakai atau melihat barang yang menjadi adiksinya tersebut (Aztri\&Milla, 2013). Oleh karena itu, mereka berharap bahwa mereka mampu bertahan dan mandiri. Klien juga memiliki keinginan untuk dapat berkarya dan menghasilkan finansial sendiri serta tidak tergantung dengan penghasilan orang lain (Guetta \& Added, 2015). Penelitian ini diharapkan mampu memahami makna partisipan tentang tantangan dan harapan selama menjalani pemulihan jangka panjang.

\section{METODE}

Metode yang digunakan dalam penelitian ini adalah studi kualitatif dengan design fenomenologi intepretatif. Pemilihan partisipan ini menggunakan porposive sampling dengan kriteria: tingkat ketergantungan tipe $\mathrm{C}$, lakilaki, usia 20 - 40 tahun, lulusan SMA/ setara, dan klien adalah post discharge panti rehabilitasi minimal 6 bulan dan menjalani pemulihan jangka panjang di komunitas. Berdasarkan kriteria tersebut, maka di dalam penelitian ini terdapat 9 partisipan yang bersedia secara sukarela untuk menceritakan pengalamannya. Tehnik wawancara yang digunakan yaitu menggunakan semi terstruktur dan in depth interview. Kemudian peneliti melakukan analisis data dengan menggunakan Intepretative Phenomenological Analysis (IPA). Selain itu peneliti telah melakukan uji etik di Universitas Brawijaya dan telah dinyatakan layak etik No 184/EC/KEPK/05/2017.

\section{HASIL}

Penelitian ini menghasilkan tiga tema berdasarkan analisis menggunakan Tema yang dihasilkan adalah (1)Mempertahankan diri dari ego dan lingkungan yang menjerumuskan; (2) Difasilitasi menjadi mandiri untuk bangkit dari keterpurukan; dan (3) Mendapat kepercayaan dan cinta kasih secara utuh.
Tema 1: Mempertahankan diri dari ego dan lingkungan yang menjerumuskan

Tema ini yaitu mempertahankan, ego, dan menjerumuskan. Arti harfiah tema ini yaitu upaya untuk bertahan dari kesadaran diri sendiri dan lingkungan yang mendorongnya hingga jatuh tersungkur. Tema ini memiliki 4 sub tema.

Sub tema satu yaitu tetap komitmen menolak ajakan pakai, diartikan sebagai tetap menjaga janji untuk menolak ajakan pakai. Makna kontekstual didapatkan dari partisipan yaitu niat partisipan unutk tetap tidak menggunakan NAPZA kembali meskipun mengalami berbagai godaan. Hal ini sesuai dengan penggalan pernyataan partisipan yaitu:

“... Ini sampai sekarang saya masih dioyakoyak terus suruh jemput bahan... Saya pusingnya di situ malahan... Ya itu tadi mbak, dioyak-oyak Bandar. Kalau yang lain kaya menghindari komunitas aja nggak masalah mbak, lha ini suruh jemput bahan kan gede banget risikonya itu. Trus itu nggak cuma satu dan dua orang $e$, itu banyak." (P.1)

"Bisa dibilang itu trigger, pemicu. Seumpama kita lagi pingin, temen kita ada yang bawa barang. Yang pasti rasa kepingin itu pasti ada. Jadi kalau aku lebih menghindar sih." (P.2)

Subtema kedua yaitu mendapatkan stigma masyarakat. Jadi secara harfiah diartikan bahwa seseorang tersebut mendapatkan ciri negatif dari masyarakat akibat pengaruh lingkungannya dahulu. Hal tersebut juga dimaknai sama secara kontekstual bahwa partisipan merasa masih diberikan penilaian negatif oleh masyarakat meskipun ia telah menjalani rehabilitasi awal.

"Saya kalau di masyarakat dapat stigma negatif setiap hari... Sama pemuda kampung itu saya tidak dianggap. Saya dikucilkan." (P.2)

"Stigma... Stigma yang pernah saya alami itu... Dulu aku itu makek itu pernah kurang uang. Di keluarga itu ngambil barang trus aku jual... Suatu saat aku itu ada barang hilang. Nah ada kejadian di daerahku yang sama persis kaya yang aku lakuin dulu itu. Mereka pasti larinya ke aku.” (P.3) 
Subtema tiga yaitu mengembalikan aset yang hilang. Sub tema tiga diartikan sebagai upaya mengembalikan modal kekayaan yang telah hilang. Makna kontekstual dari sub tema ini yaitu partisipan mengalami kesulitan untuk mengembalikan dan mengupayakan kebutuhan finansial keluarga. Pernyataan yang mendukung subtema ini yaitu:

"Semua hutang tapi ada 1 hutang yang nggak, sertifikat rumah. Sertifikat rumah itu kan saya gadaikan juga... Sampai sekarang saya masih cicil itu sertifikat rumah itu... Jadi ya belum bisa main-main, paling ya sekedarnya aja." (P.7)

Sub tema terakhir yaitu menjauhi lingkungan lama. meninggal teman dan lingkungan dahulu yang pernah ada. Makna kontekstual juga tidak berbeda dari makna harfiah kesulitan partisipan dalam menghindari lingkungan lama. Hal ini terlihat dari pernyataan partisipan yaitu:

"Menjauhi orang baik, menjauhi orang yang baik sama kamu. Itu yang berat. Bener kalau ada teori, habis pakek kamu pindah kota aja, cabut dari kota itu. Sebaik-baiknya orang tetep akibatnya jelek.” (P.9)

Tema ini secara kontekstual diartikan sebagai kemampuan individu yang telah mengalami ketergantungan zat adiktif untuk mempertahankan diri dalam kondisi maintenance.

Tema 2: Difasilitasi menjadi mandiri untuk bangkit dari keterpurukan

Tema ini diartikan sebagai diberikan fasilitas untuk tidak bergantung pada orang lain agar dapat bangun kembali dari kondisi yang parah. Tema ini memiliki 3 sub tema. Sub tema pertama yaitu dapat bangkit dari keterpurukan NAPZA. Sub tema dapat diartikan sebagai dapat bangun kembali dari kondisi yang parah karena NAPZA. Makna kontekstual didapatkan bahwa kemampuan klien untuk tetap berjuang dalam proses pemulihan dan tetap melangkah ke depan.

"Saya tidak mau masuk ke dalam lubang yang sama. Sekarang dinikmati dan disyukuri..." (P.6)
"Memperbaiki apa yang sudah saya lakukan. Memperbaiki dan melangkah buat ke depan lah...”(P.8)

Sub tema 2 yaitu dapat menjalankan roda ekonomi keluarga. secara harfiah sub tema diartikan sebagai dapat menjalankan kegiatan dalam bidang perekonomian di dalam keluarga. Makna kontekstual yaitu partisipan berharap ia masih dapat meneruskan dan memberikan kebutuhan ekonomi bagi keluarga, sehingga kebutuhan finansial terpenuhi.

\section{"Ya kalau keluarga, semuanya bisa} kecukupan, buat hidup." (P.6)

Sub tema terakhir yaitu ingin merasakan kehadiran orang tersayang secara utuh. Maka arti dari sub tema 3 yaitu ingin merasakan sekumpulan orang yang disayang hadir secara penuh. Makna kontekstual yaitu partisipan menginginkan orang-orang disekitarnya termasuk keluarga memahami apa yang dia inginkan dan menjadi beban pikirannya.

"Aku pingin diingertiin, dalam hal aku punya hobi, aku punya kesulitan ini, aku punya beban, tolong bantu aku... Pingin bahagia... Aku bisa kumpul sama keluarga, bisa kumpul sama temen, ngeband, bisa lancar hubunganku dengan cewekku." (P.3)

Difasilitasi menjadi mandiri untuk bangkit dari keterpurukan, secara kontekstual dimaknai sebagai sesuatu yang diharapkan partisipan dalam menjalani proses pemulihan.

Tema 3: Mendapat kepercayaan dan cinta kasih secara utuh.

Arti dari tema 3 adalah mendapatkan sesuatu yang dipercaya benar dan kasih sayang secara penuh. Tema ini terdiri dari 4 sub tema. Sub tema satu yaitu sub tema 1 diartikan sebagai mendapatkan kembali keyakinan yang telah menjadi berkurang atau hilang. Makna kontekstual sub tema ini yaitu partisipan merasa bahwa ia telah menodai kepercayaan dari orang-orang tersayangnya, sehingga mereka ingin mendapatkan kepercayaan tersebut kembali.

"Dari dulu sampai sekarang, bapakku sambung ini, dia itu nggak apa yaa... Terlalu nggak percaya sama aku kalau masalah 
uang. Jadi ibuku kalau ngasih uang itu ya sembunyi-sembunyi... Sekarang itu aku sama bapakku sambung ini kan nggak terlalu cocok sih. Beda banget gitu lho... Bapakku sambung itu terlalu kolot dan agamis.” (P.3)

"Kepercayaan... Yang pertama ya kepercayaan dari diri sendiridulu, kalau bisa pulih, mampu pulih... kalau mereka temen ya tetep bisa percaya kalau saya tetep teman mereka..." (P.8)

Sub tema 2 yaitu difasilitasi untuk mengutarakan pikiran dan perasaan secara terbuka. Secara harfiah diartikan sebagai diberikan fasilitas untuk mengungkapkan apa yang dirasakan dan dipikirkan. Secara kontekstual, dapat diartikan bahwa partisipan membutuhkan seseorang yang mampu memberikan solusi dan ia mengutarakan apa yang dipikirkan secara terbuka.

"Konseling itu sangat berarti... Konseling itu sangat penting buat aku. Kalau makin lama dipendam makin lama, balik lagi. Konseling. Gimana caranya biar kita bisa nahan emosi. Kalau kita bisa berhasil nahan emosi, disitu kita bisa lepas dari semuanya." (P.2)

Selanjutnya sub tema 3 menginginkan kehadiran diri orang tersayang. Sub tema ini diartikan sebagai memiliki keinginan untuk membuat hadir sekumpulan orang yang di sayang. Makna secara kontekstual didapatkan bahwa partisipan membutuhkan orang-orang yang mampu memberikan kekuatan dan motivasi untuk proses pemulihan yang sedang dijalani.

"Aku butuh kehadirannya saja (keluarga). Kehadiran yang... ini mamahku, bapakku, kakakku, aku juga sekarang ngak bisa manja kan Mbak... Manja itu juga dulu salah satu factor ku yaa... kalau aku manja terus ya... "siapa loo". Jadi yaa aku pingin mereka selalu ada untukku...." (P.3)

Sub tema terakhir yaitu Membutuhkan rengkuhan Tuhan. Sub tema ini diartikan sebagai membutuhkan kedekatan dengan Tuhan. Makna kontekstual diartikan bahwa partisipan menganggap Tuhan merupakan sumber kekuatan dalam menghadapi proses pemulihan.

\begin{abstract}
"Kasih Tuhan... Ketika saya mengantuk ditidurkan oleh Tuhan, ketika saya bangun dibangunkan Tuhan, dan ketika bergerak, saya digerakkan oleh Tuhan.” (P.5)
\end{abstract}

Secara kontekstual, tema ini dilihat dari pernyataan partisipan mengenai segala hal yang dibutuhkan selama menjalani proses pemulihan. Kebutuhan tersebut merupakan salah satu upaya dalam mencegah relaps.

\section{PEMBAHASAN}

Upaya untuk tidak kembali pada dunia NAPZA selalu diupayakan oleh penyalahguna NAPZA itu sendiri. Hal ini dikarenakan setelah keluar dari panti rehabilitasi, godaan besar bagi klien ketergantungan NAPZA yaitu ketika mereka bertemu dengan teman pemakai atau lingkungan baru, tetapi yang akrab dengan NAPZA. Hal ini sesuai dengan keterangan yang diberikan partisipan bahwa ada rasa ingin menggunakan kembali zat tersebut jika melihat teman pakai atau melihat barang yang menjadi adiksinya tersebut (Aztri\&Milla, 2013).Hal ini sesuai dengan capital recovery bahwa memahami dirinya menjadi bagian dari komunitas yang menjalani pemulihan terhadap zat adiksi. Sehingga, dia akan lebih mengenal dirinya bahwa dengan menjaga kesadaran tersebut maka ia akan menjaga dirinya dari bahaya relaps (Gueta \& Addad, 2015)danmereka memilih pindah di tempat yang baru untuk mendapatkan lingkungan dan suasana yang baru dan jauh dari NAPZA tersebut.

Tantangan-tantangan baru akan muncul untuk klien ketergantungan NAPZA antara lain diskriminasi, stigma, sosioekonomi, interpersonal konflik, dan kurangnya dukungan sosial. Namun, sosioekonomi dirasa tantangan terbesar bagi klien karena mereka merasa bahwa tidak punya daya, tidak mempunyai pekerjaan, dan penghasilan yang dirasa kurang mencukupi. Selain itu, keinginan ingin pakai atau craving merupakan kesulitan tersendiri yang dirasakan oleh klien. Mereka terkadang merasa ada sugesti ketika melihat teman pakai atau melihat barang (Yang, Mamy, Gao, \& Xiao, 2015). Selain tantangan, klien dengan ketergantungan zat adiktif juga memiliki harapan bahwa mereka akan ingin menjadi mandiri.Kondisi sosioekonomi ini akan berdampak pada kondisi finansial. Pada klien dengan ketergantungan NAPZA, mereka akan 
mengalami gangguan saat menjalani roda ekonomi keluarga (Yang, Mamy, Gao, \& Xiao, 2015). Klien juga memiliki keinginan untuk dapat berkarya dan menghasilkan finansial sendiri serta tidak tergantung dengan penghasilan orang lain. Masalah ketergantungan zat adiktif membuat mereka kehilangan pekerjaan profesional, bahkan perumahan (Guetta \& Addad, 2015).

Upaya untuk menanggulangi pengangguran dan kejahatan yang diakibatkan karena ketergantungan NAPZA tersebut, maka perlu diberikan pelatihan pada klien yang mengalami ketergantungan NAPZA. Hal ini bertujuan untuk menambah pengetahuan, ketrampilan, dan pengalaman klien sebagai upaya kesiapan diri klien ketika berada di komunitas (Neale et al., 2014).Selainitu, klien juga membutuhkan kepercayaan dan rasa dimiliki. Hal ini berhubungan dengan kepuasan seseorang pada pencapaiannya, sesuai dengan hierarki Maslow. Rasa ini merupakan dasar dari konsep kesehatan mental yang berhubungan dekat dengan fungsi sosial dan psikologis. Salah satu bentuk rasa ingin dihargai yaitu adanya kelompok peer bagi klien. Hal ini dimaksudkan untuk memberikan semangat, dorongan agar tetap menjaga abstinensi, dan menemukan keterbukaan melalui sharing dan konsultasi (Guetta \& Addad, 2015). Konseling ini mampu membantu mereka untuk memberikan masukan-masukan yang spesial ketika klien menghadapi stress (Fareo, 2012), menurunkan tingkat stress, kecemasan, dan depresi (Gyllenstern \& Palmer, 2005). Kebutuhan yang lain yaitu kasih sayang Tuhan. Hasil penelitian menunjukkan bahwa klien yang mengalami adiksi butuh petunjuk dari Tuhan dalam menjalani pemulihan jagka panjang. Agama merupakan dasar rasionalitas sebagai upaya untuk mengkonversi dan merekonstruksi dasar kepercayaan individu secara identitas dan gaya hidup, dapat mengikat \& memagari perilaku individu (White \& Kurtz, 2006).

\section{SIMPULAN}

Klien yang mengalami ketergantungan dan menjalani pemulihan jangka panjang memiliki harapan untuk hidup kembali. Harapan tersebut antara lain mereka ingin tetap bekerja dan dihargai di masyarakat. Selain itu, mendapat kasih saying Tuhan juga keinginan dan harapan dalam upaya kekuatan spiritual selama menjalani proses pemulihan tersebut.

\section{DAFTAR PUSTAKA}

Aztri \& Milla. (2013). Rasa Berharga dan Pelajaran Hidup Mencegah Kekambuhan Kembali Pada Klien ketergantungan Narkoba Studi Kualitatif Fenomenologis. Jurnal Psikologi. Volume 9, Nomor 1, Juni

Betty, T., \& Panel, C. (2007). What is recovery? A working definition from the Betty Ford Institute. Journal of Substance Abuse Treatment, 33(3), 221228.

https://doi.org/10.1016/j.jsat.2007.06.00 1.

Fareo, Dorcas Oluremi. (2012). Drug abuse among Nigerian adolescents strategies for counselling. The Journal of International Social Research. Vol. 5. Issue 20. Winter 2012.

Fredericks, J., \& Samuel, E. (2014). Drugs and Recovery: A Qualitative Study in Atlantic Canada. Aijssnet.Com, 3(2), 28-34. Retrieved from http://www.aijssnet.com/journals/Vol_3 _No_2_March_2014/4.pdf.

Gyllenstern \& Palmer (2005). Can coaching reduce workplace stress? A quasi experimental study. International Journal of Evidence Based Coaching and Mentoring. Vol. 3, No. 2, Autumn 2005.

Gueta, K., \& Addad, M. (2015). Women â€ ${ }^{\mathrm{TM}}$ s Studies International Forum A house of cards: The long-term recovery experience of former drug-dependent Israeli women 论, 论弥. Women's Studies International Forum, 48, 18-28. https://doi.org/10.1016/j.wsif.2014.10.0 03.

Saltz, Larson, LaBelle, Richards, \& Samet. (2008). The case for chronic management for addiction. National Institute of Health. J Addict Med. June 1; 2 (2) 
White \& Kurzt. (2006). The varieties of recovery experience: a primer for addiction treatment professionals and recovery advocates. William White Papers.

Yang, Mamy, Gao, \& Xiao. (2015). From abstinence to relapse: a priliminary qualitative study of drug users in a compulsory drug rehabilitation center in Changsha, China. Drug User's Experiences During Abstinence. June 24.2015 .2 Doi: 10.1371/journal.pone.0130711. 